\title{
Open Access: trends and strategies after Berlin5
}

\author{
Elena Giglia, University of Turin \\ elena.giglia@unito.it \\ Marialaura Vignocchi, Alma Mater Studiorum, University of Bologna \\ marialaura.vignocchi@unibo.it
}

After the three day debate at the International Conference Berlin5: from practice to impact. Consequences of knowledge dissemination ${ }^{1}$,(Padua, Italy, Sept. $19^{\text {th }}-21$ th 2007 ), it was clear to all participants that Open Access is a simple concept, but a complex reality to achieve, because of the great multitude of players and interests involved, as Sijbolt Noorda (European Universities Association) observed in the opening keynote speech.

The conference offered an overview of current practices, focused on critical issues and contributed suggestions for future viable pathways. In particular, the main topics under discussion have been:

- access to digital resources with respect both to legal and technical issues;

- sustainability of OA business models;

- quality both in terms of content validation through peer-review and digital long-term preservation;

- impact of OA on research practices: e-science, data sharing;

- varieties of OA: there is no single solution, but rather many community-oriented strategies and tools .

After the welcome addresses on Wednesday, $19^{\text {th }}$, Sijbolt Noorda introduced the debate about the challenges of OA and the possibilities to achieve a win-win solution suitable for all the stakeholders participating in the scholarly communication process, suggesting that the complexity of the research community - what makes sense for historians it does not for engineers - must be treasured and must be taken into account if we want that the OA model is accepted. Noorda also pointed to the potentiality of digital technologies, that should offer much more than a mere surrogate of the traditional way of publishing.

In the first session of the second day, Status Report by signatories, speakers representative of research institutions from all over the world which signed the Berlin Declaration illustrated the projects and the state of the art of OA initiatives in their countries: Fred Friend (JISC, UK) presented the deep commitment and support of British institutions to the OA choice, the mandatory policies of the funding agencies, and new projects like the "Copyright knowledge base", to implement the RoMEO/SHERPA database. Jens Vigens (CERN), talking about the CERN experience, pointed out that a mandatory policy is not enough and researchers should be offered services and incentives. Roberto delle Donne showed the work in progress supported by the Italian Conference of University Rectors in order to raise awareness among Italian researches, and provide guidelines and best practices. Subbiah Arunachalam presented the strenghts and weaknesses of the Indian experience, while Hiroya Takeuchi gave a survey of the early steps of OA in Japan, after a long silence.

\footnotetext{
${ }^{1}$ Papers can be searched on the conference website, at http://www.aepic.it/conf/papers.php? $\mathrm{cf}=10$.
} 
The session dedicated to the Transition to the Golden Road: models, experiences, criticism, saw Rudolph Schimmer (Max Planck Inst.) take a firm position in favour of gold OA, based on the consideration that journals offer more immediate practical advantages than the open archives that are still far from scaling up and providing effective services, with few notable exceptions. Commenting the "author pays" model Schimmer warned against the systematic diversion of research funds: the challenge would be to synchronize the library and research budgets and to device communicative and administrative procedures to redirect this new consolidated budget. Recognizing that digital technology and economy favour the separation of research quality certification from distribution and archiving, Chris Armbruster (Research Network 1989) argued for digital libraries and open repositories to take the functions of electronic registration, dissemination and archiving, while publishers might best concentrate on certification and navigation services. Among these overlay services the most innovative could be usage and impact metrics, citation and co-citation tracking, data and text mining, and semantic enrichment. However, these services require that research publications and data are freely available, on a non-exclusive basis. As regards the file format, a lot of voices raised against the PDF as a technological barrier to deep access.

Salvatore Mele (CERN) presented the innovative business model carried out by the SCOAP3 ${ }^{2}$ project, developed within the community of the High Energy Physicists that have been effectively communicating through arXiv for more than fifteen years. The project aims at converting to Open Access the whole scientific production in the field on the basis of common licenses negotiated among the stakeholders - funding agencies, research institution, libraries and publishers. According to the license, the publishers should be paid by funding agencies and research institutions to ensure peer-review process and provide open access publications. The High Energy Physics community is very small and their project is not so easily portable.

A parallel session focused on Open Access in the Humanities and Social Sciences, trying to cope with the specificity of this area, their different needs and research practices.

In the afternoon, the conference had two more parallel sessions: Open Access in the Developing countries and Open issues in Open Access. The first presented the significant experiences of the FAO (UN), and of two OA publishers represented by Barbara Kirsop (BioLine Int) and D.K.Sahu (Medknow). Both the contributions stressed the role played by $\mathrm{OA}$ in expanding access to research results and therefore in advancing knowledge and scientific progress. Statisics from India, Brazil, Africa showed how local research is gaining international impact. Mr. Saku also showed that the OA policy of Medknow which charges no fee neither to the authors nor to the online readers, has not negatively influenced the number of subscriptions to the print editions. In addition the increased visibility of the journals has brought a submission rate rise from all over the world.

\footnotetext{
${ }^{2}$ More information: Towards Open Access Publishing in High Energy Physics - Report, available at http://openaccess.web.cern.ch/Open-Access/Scoap3WPReport.pdf.
} 
Open issues in Open Access were discussed among the others by Max Voegler, who presented The Knowledge Exchange Project, a collaboration between DEFF (Denmark's Electronic Research Library), DFG (Deutsche Forschungsgemeinschaft), JISC (JOINT Information Systems Committee) and SURF, whose mission is to develop closer working relationships between partner organisations in order to increase the return on national investment in ICT infrastructure, services and projects in higher education and research ${ }^{3}$.

The technological and political European framework was presented during a dedicated session in the late afternoon. Celina Ramjoué (European Commission, DG Research) explained all the steps taken by the European Community to demonstrate the commitment to OA of the EU both as a policymaker and a funding body. According to the Lisbon Strategy, the dissemination of research outputs plays a fundamental role in enhancing the European competitiveness. Pedro Ferreira (The Knowledge Society Agency) outlined new infrastructures for knowledge creation, dissemination and sharing (like GEANT2, EGEE, DRIVER $^{4}$ ).

On the third and last day the conference split again into two parallel events.

The ESF (European Science Foundation) and DFG (Deutsche Forschungsgemeinschaft) Workshop on Shared responsibilities in sharing research data provided an introductory session where Peter Murray-Rust (Cambridge University, UK) re-purposed his term "Open Data" to better describe access to, and re-use of, data. He focused on text-mining techniques developed in chemistry to rapidly index the scientific chemical web and add significant semantic value. He pointed out that this process works only in an Open Access environment. To fully achieve Open Data some issues have to be addressed since traditional requirements of Open Access communication model do not automatically apply to data: easiness of access, standardization, description, permanent identifier, storage, privacy and appropriate policies. The two following workshop sessions tried to outline these issues from the Stakeholders' Perspective. Yukiku Fukasaku (Innovomond sarl) presented the principles and the guidelines approved by the OECD about data sharing and the recent initiatives by CODATA and GICSI $^{5}$. Peter Doorn (DANS, NL) gave a portrait of the efforts to increase internationalisation and computerisation in the social sciences and the humanities, while pointing at the need of a real pan-European data infrastructure, as shown in the Roadmap of ESFRI ${ }^{6}$. The Research Funding Agencies' Perspective was represented by Belinda Soto (National Institutes of Health, US) who focused on the means to overcome technological challenges in terms of interoperability and networks of databases. Mark Thorley (Natural Environment Research Council, UK) examined the similarities and the differences in data management and data sharing across the disciplines represented by the seven UK Research Councils. Indeed a leitmotiv of the conference has been that each disciplinary field needs its own Open Access strategies and policies, each having its means and ways of communication. Chris Greer (National Science Foundation, USA) showed the NSF Vision ${ }^{7}$ for $21^{\text {st }}$ Century Discovery that

\footnotetext{
${ }^{3}$ See http://www.knowledge-exchange.info/.

${ }^{4}$ Available at http://www.geant2.net/, http://www.eu-egee.org/, http://www.driver-repository.eu/.

${ }^{5}$ OECD Principles:

http://webdomino1.oecd.org/horizontal/oecdacts.nsf/Display/3A5FB1397B5ADFB7C12572980053C9D3?Open

Document. See also http://www.codata.org/ and http://www.codata.org/wsis/GICSI-prospectus.html.

${ }^{6}$ European Strategy Forum on Research Infrastructure, see http://cordis.europa.eu/esfri/home.html

${ }^{7}$ Available at http://www.nsf.gov/pubs/2007/nsf0728/nsf0728.pdf
} 
is the development of a system of data collections that will consist of a wide range of data aggregations and managing organizations networked together and designed to contribute to the emerging global information commons. Carlos Ferreira de Morais Pires (UE, GEANT unit and e-infrastructure - DG Information Society) presented the European framework and suggested that some "continuums" will have to be created between past, present and future between raw experimental data and publications, between different scientific disciplines; between different institutions, between research and education.

The parallel workshop Open Access in the Scholarly Communication in Italy was divided into three sessions. The first one, Open Access and Rights Management Policies, was chaired by Fiorello Cortiana (Internet Governance Forum), who sketched out the vision of a multistakeholders'culture of accessibility, in which "open" stands also for openness of the evolving situation with no possibility to be precluded for the future. Indeed, the more the infrastructure are open, the easier it will be to experiment with new features. Interoperability ought to be not only technological but also cognitive and cultural in order to produce a real collective contribution to knowledge. The Magistrate Giuseppe Corasaniti gave an overview on the prejudicial opinions and critical positions that seems to prevent any opening revision of the legislative framework on intellectual property in Italy. He showed that the European Directives points to harmonization but leaves great freedom to each single country as regards exceptions and limitations. The matter is not to rewrite the provision completely, but to better focus its application to better adapt it to the new digital environment. Juan Carlos De Martin (Politecnico, Turin) argued against unnecessary legal and technical barriers to access while presenting the Science Commons initiative and its new projects, such as MTA, ${ }^{8}$ and Neurocommons. The latter intends to create an Open Source knowledge management system for neuroscience research by applying text mining and natural language processing to open biomedical abstracts., Antonella De Robbio (University of Padua) gave a precious framework of the Authors' Rights considered as a "right to access", not a barrier - this is a strategic issue for an effective Open Access. She focused on the policies - and this was another key point of Berlin 5 - that each University ought to establish in order to identify and manage IP rights more consciously. In the sessions dedicated to the Sciences, Loriano Bonora (SISSA) discussed the central role of the peer-review, the limitations of current practices and indicators while presenting the new tools and opportunities offered by the Open Access environment in the field of the research assessment. Lorenzo Moja (Mario Negri Institute, Milan) presented ECCE, a free Continuing Medical Education virtual learning system trying to put Open Access into practice ${ }^{9}$. In the Humanities session, Maria Chiara Pievatolo (University of Pisa) presented her metaphor of "incomplete library" to represent the current situation. Some resources are freely accessible, some other no, while communities especially in the humanities are disconnected, lacking of an organic communication sharing system. This seems to be true especially in Italy. The solution could be freedom of content (for "information") and communities of knowledge (for "wisdom"). Assuming that this situation of fragmentation and delay may offer the opportunity to try out new criteria, she compared the actual peer review process to a "Kafka court of law" with invisible judges, no sure criteria,

\footnotetext{
${ }^{8}$ Materials Transfer Agreement Project, available at http://sciencecommons.org/projects/licensing/ and Neurocommons, available at http://sciencecommons.org/projects/data/.

${ }^{9}$ Educazione Continua Clinical Evidence, see http://aifa.progettoecce.it/.
} 
unclear laws, summary and secret trials... who would like to be judged by such a court? She suggested as a solution to adopt open peer review, soft peer review, retroactive peer review with the instruments of Web 2.0 or overlay journals. She contested also the Impact Factor criterion and the overpower of some publishers and some journals which have become a sort of "brand" that legitimate the research, with the result of making the dialectic and dynamic process of knowledge a static and oligarchic one. Open Access can assure a public place to debate, like the Athens's court. Gino Roncaglia (University of Tuscia) tried to point out links between Institutional Repositories and Learning Content Management Systems. He made the proposal to archive LO in the repositories, describing them with DC metadata to ensure the harvesting, and associate a LOM metadata file to make them collectable and re-usable in a learning environment; Gian Maria Varanini (University of Verona) presented the "Reti Medievali" net, a project that offers text, working tools and analysis in Medieval and Modern history.

Alma Swan (Key Perspectives, UK) closed the conference with an enthralling overview of the key strategies and tactics - all of them possible, reasonable, sensible - for the future of the Open Access. Given the lack of awareness among the scholars themselves, Alma Swan recommended a sort of "serving suggestions" to have the message of the OA reach the stakeholders. She suggested to use testimonies, facts and figures about impact, visibility, usage and download. On the financial side, the purpose was to "reorganize" money in the system, to show the positive result of OA policy on research investment to funding agencies, as the OECD Report on scientific publishing has demonstrated. She also stressed the need for mandatory OA policies in order to collect the native version of scientific papers. As a matter of fact, the scholarly community is not yet completely aware of the potential of the Web, both as a network of communication and a cradle for new tools for research practice.

Alma Swan concluded her speech stressing the importance of lobbying and counter lobbying initiatives, finally quoting from Gandhi:

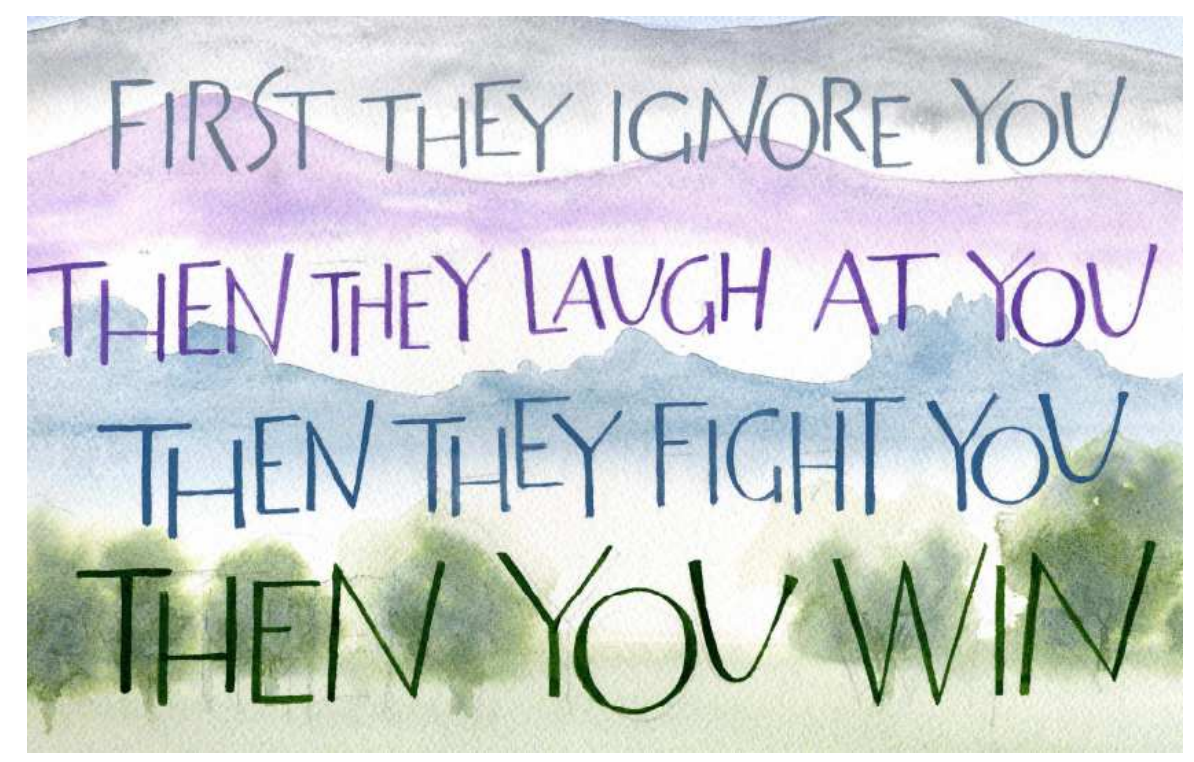

